\title{
The Molecular Structure of Gaseous Bismuth Trichloride Determined by Electron Diffraction
}

\author{
Arne Haaland, ${ }^{a, *}$ Jens Hougen, ${ }^{a}$ Svein Samdal ${ }^{b}$ and Janos Tremmel ${ }^{c}$ \\ aDepartment of Chemistry, University of Oslo, P.O. Box 1033, N-0315 Oslo 3, 'Oslo College of Engineering, \\ Cort Adelers gt. 30, N-0254 Oslo 2, Norway and 'Structural Chemistry Research Group of the Hungarian \\ Academy of Sciences, Budapest, P.O. Box 117, H-1431, Hungary
}

\begin{abstract}
Haaland, A., Hougen, J., Samdal, S. and Tremmel, J., 1988. The Molecular Structure of Gaseous Bismuth Trichloride Determined by Electron Diffraction. Acta Chem. Scand., Ser. A 42: 409-412.

Gas-phase electron diffraction data for $\mathrm{BiCl}_{3}$ have been collected with a nozzle temperature of $185^{\circ} \mathrm{C}$. The data are consistent with a model of $C_{3 \mathrm{v}}$ symmetry having $r_{\mathrm{a}}(\mathrm{Bi}-\mathrm{Cl})=242.3(5) \mathrm{pm}$ and $\angle \mathrm{ClBiCl}=97.3(2)^{\circ}$. Estimated standard deviations are given in units of the last digit. Secondary bonding $\mathrm{Cl} \rightarrow \mathrm{Bi}$ in the solid phase increases the average $\mathrm{Bi}-\mathrm{Cl}$ bond distance by $8 \mathrm{pm}$ and reduces the average $\angle \mathrm{ClBiCl}$ angle by $6^{\circ}$.
\end{abstract}

Dedicated to Professor Otto Bastiansen on his 70th birthday

While accurate structure parameters are available for the gaseous Group 15 trichlorides $\mathrm{NCl}_{3},{ }^{1} \mathrm{PCl}_{3},{ }^{2} \mathrm{AsCl}_{3}{ }^{3}$ and $\mathrm{SbCl}_{3}{ }^{4}$, accurate data on gaseous $\mathrm{BiCl}_{3}$ are lacking, perhaps because of its high reactivity and low volatility. The present study was undertaken to fill the gap.

\section{Experimental}

Commercially available $\mathrm{BiCl}_{3}$ (Fluka) was used without further purification. Electron diffraction data were recorded on the EG-100 A apparatus in Budapest, ${ }^{5}$ with nozzle-to-plate distances of about 50 (three plates) and $19 \mathrm{~cm}$ (four plates). The sample container and nozzle were made of molybdenum, ${ }^{6}$ and the vaporising temperature was $183 \pm 5^{\circ} \mathrm{C}$. Mass spectra recorded under similar conditions contained no peaks indicating the presence of associated species or impurities.

Atomic intensities ("backgrounds") were subtracted in the manner described by Hargittai and Hargittai. ${ }^{7}$ Atomic scattering factors $f_{z}^{\prime}(s)$ were taken from Schäfer et al. ${ }^{8}$ Molecular intensities were modified through multiplication by

*To whom correspondence should be addressed. $s /\left|f_{\mathrm{Bi}}^{\prime}(s)\right|\left|f_{\mathrm{Cl}}^{\prime}(s)\right|$. The $50 \mathrm{~cm}$ curves extended from $s=20$ to $140 \mathrm{~nm}^{-1}$ with increments of $1.25 \mathrm{~nm}^{-1}$. The $19 \mathrm{~cm}$ data were of lower quality and could not be brought into agreement with calculated intensities when $s>200 \mathrm{~nm}^{-1}$. The structure refinements were therefore based on intensities ranging from $s=105.0$ to $200.0 \mathrm{~nm}^{-1}$ with increments of $2.50 \mathrm{~nm}^{-1}$ (see Fig. 1).

The molecular symmetry was assumed to be $C_{3 \mathrm{v}}$, and $r_{\mathrm{a}}$ distances and vibrational amplitudes $l$ refined by least-squares calculations on the intensity data. The best values are listed in Table 1 . An experimental RD curve and a difference curve are shown in Fig. 2.

\section{Discussion}

Internuclear distances $\left(r_{\mathrm{a}}\right)$, root-mean-square vibrational amplitudes $(l)$ and valence angles of the Group 5 trichlorides as determined by gas-phase electron diffraction are listed in Table 1 . Bond distances and valence angles in the gaseous Group 15 element compounds $\mathrm{ElH}_{3}, \mathrm{El}\left(\mathrm{CH}_{3}\right)_{3}$ and $\mathrm{ElCl}_{3}$ are displayed in Fig. 3 .

As expected, all bond distances increase as the group is descended. The $\mathrm{El}-\mathrm{H}$ bond distance curve from $\mathrm{El}=\mathrm{N}$ to $\mathrm{El}=\mathrm{Sb}$ and the $\mathrm{El}-\mathrm{Cl}$ bond 

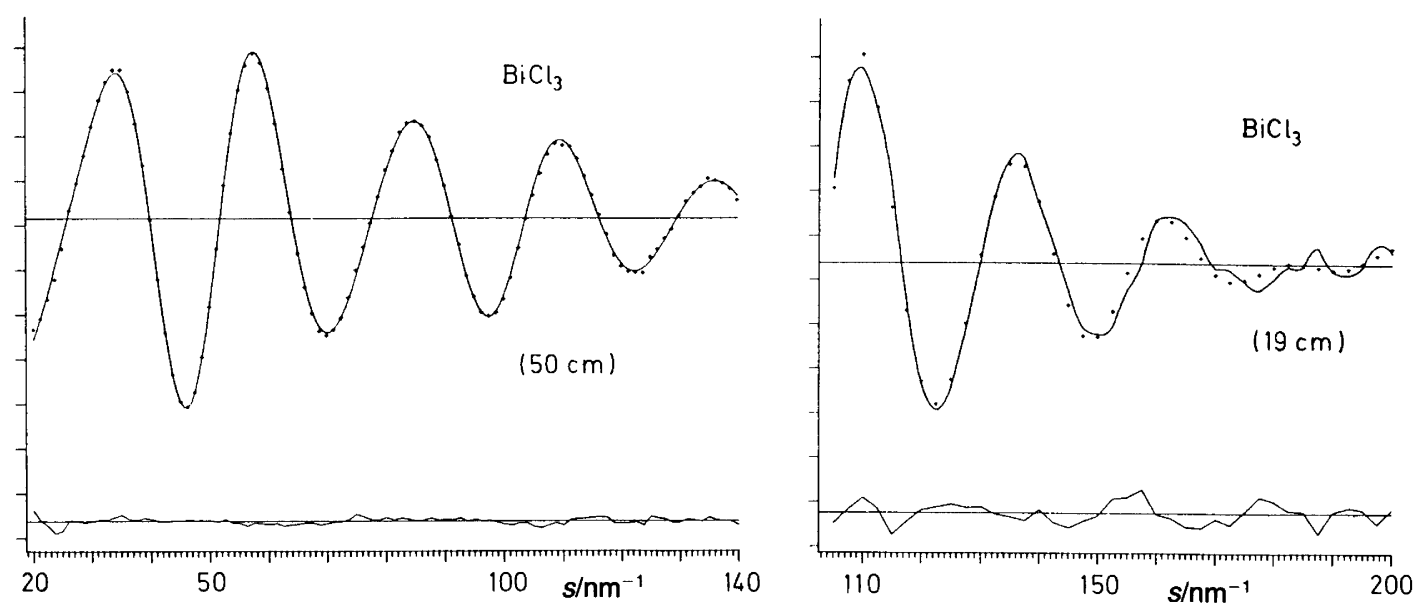

Fig. 1. Modified molecular intensity curves and difference curves for $\mathrm{BiCl}_{3}$.

distance curve from $\mathrm{El}=\mathrm{P}$ to $\mathrm{El}=\mathrm{Bi}$ are nearly parallel to the El-C bond distance curve. Only the $\mathrm{N}-\mathrm{Cl}$ bond distance in the very unstable compound $\mathrm{NCl}_{3}$ breaks the pattern by being about 10 pm longer than predicted by extrapolation from the other bond distances. The shape of the bond distance curves have been discussed elsewhere. ${ }^{9}$

It is well known that the valence angles in the Group 15 trihydrides approach $90^{\circ}$ (or rather $91^{\circ}$ ) as the group is descended. The valence angles of the trichlorides, on the other hand, approach $97^{\circ}$. The reason for the larger $\mathrm{ClElCl}$ angles is not clear: If the angle was determined by non-bonded $\mathrm{Cl} \cdots \mathrm{Cl}$ repulsions, it would decrease more rapidly with increasing $\mathrm{El}-\mathrm{Cl}$ bond distance; on going from $\mathrm{SbCl}_{3}$ to $\mathrm{BiCl}_{3}$, the $\mathrm{Cl} \cdots \mathrm{Cl}$ distance increases by $15 \mathrm{pm}$ but the valence angle remains unaltered.

The monotonic increase of the bond vibra- tional amplitudes from $\mathrm{As}$ to $\mathrm{Bi}$ and of the nonbonded $\mathrm{Cl} \cdots \mathrm{Cl}$ amplitudes from $\mathrm{N}$ to $\mathrm{Bi}$, reflect both increasing gas temperature and decreasing stretch and bend force constants.

The decrease in the bond vibrational amplitude on going from $\mathrm{NCl}_{3}$ to $\mathrm{PCl}_{3}$ is undoubtedly due to the decrease in zero point vibrational energy resulting from a doubling of the mass of the Group 15 element: The bond-stretch force constants are very similar, viz. $f(\mathrm{~N}-\mathrm{Cl})=2.73$ mdyn $\AA^{-1}$ and $f(\mathrm{P}-\mathrm{Cl})=2.83$ mdyn $\AA^{-1},{ }^{2,10}$ and the vibrational amplitudes at $298 \mathrm{~K}$ calculated from the molecular force fields are $l(\mathrm{~N}-\mathrm{Cl})=5.5 \mathrm{pm}$ and $l(\mathrm{P}$ $\mathrm{Cl})=5.1 \mathrm{pm} \cdot{ }^{1,2}$

The structure of the $\mathrm{BiCl}_{3}$ molecule is significantly modified when it enters the crystalline phase: In the crystal, each $\mathrm{Bi}$ atom enters into "secondary bonding" interactions with five $\mathrm{Cl}$ atoms from neighbouring molecules. ${ }^{11}$ These in-

Table 1. Molecular structures of the Group 15 element trichlorides, $\mathrm{EICl}_{3}$, as determined by gas-phase electron diffraction. Estimated standard deviations in parentheses in units of the last digit.

\begin{tabular}{|c|c|c|c|c|c|c|}
\hline & $\begin{array}{l}\text { Temp } \\
/{ }^{\circ} \mathrm{C}\end{array}$ & $\begin{array}{l}r_{\mathrm{a}}(\mathrm{El}-\mathrm{Cl}) \\
/ \mathrm{pm}\end{array}$ & $\begin{array}{l}l(\mathrm{El}-\mathrm{Cl}) \\
/ \mathrm{pm}\end{array}$ & $\underset{\rho}{\angle \mathrm{CIEICl}}$ & $\begin{array}{l}r_{\mathrm{a}}(\mathrm{Cl} \cdots \mathrm{Cl}) \\
/ \mathrm{pm}\end{array}$ & $\begin{array}{l}l(\mathrm{Cl} \ldots \mathrm{Cl}) \\
/ \mathrm{pm}\end{array}$ \\
\hline $\mathrm{NCl}_{3}{ }^{\mathrm{a}}$ & 25 & $175.7(2)$ & $6.1(3)$ & $107.1(5)$ & 283 & $7.4(2)$ \\
\hline $\mathrm{PCl}_{3}{ }^{\mathrm{b}}$ & 27 & 203.9(1) & $5.0(1)$ & $100.3(1)$ & 313 & $8.3(2)$ \\
\hline $\mathrm{AsCl}_{3}{ }^{c}$ & 18 & 216.1(1) & $4.7(1)$ & $98.6(2)$ & 327 & $9.5(3)$ \\
\hline $\mathrm{SbCl}_{3}{ }^{d}$ & 70 & $233.1(1)$ & $6.3(2)$ & $97.2(4)$ & 350 & $14.7(6)$ \\
\hline $\mathrm{BiCl}_{3}{ }^{e}$ & 185 & $242.3(5)$ & $6.8(3)$ & $97.3(2)$ & 364 & $16.7(5)$ \\
\hline
\end{tabular}

${ }^{a}$ Ref. 1. The temperature is not explicitly stated. ${ }^{b}$ Ref. $2 .{ }^{c}$ Ref. 3. ${ }^{d}$ Ref. $4 .{ }^{a}$ This work. 


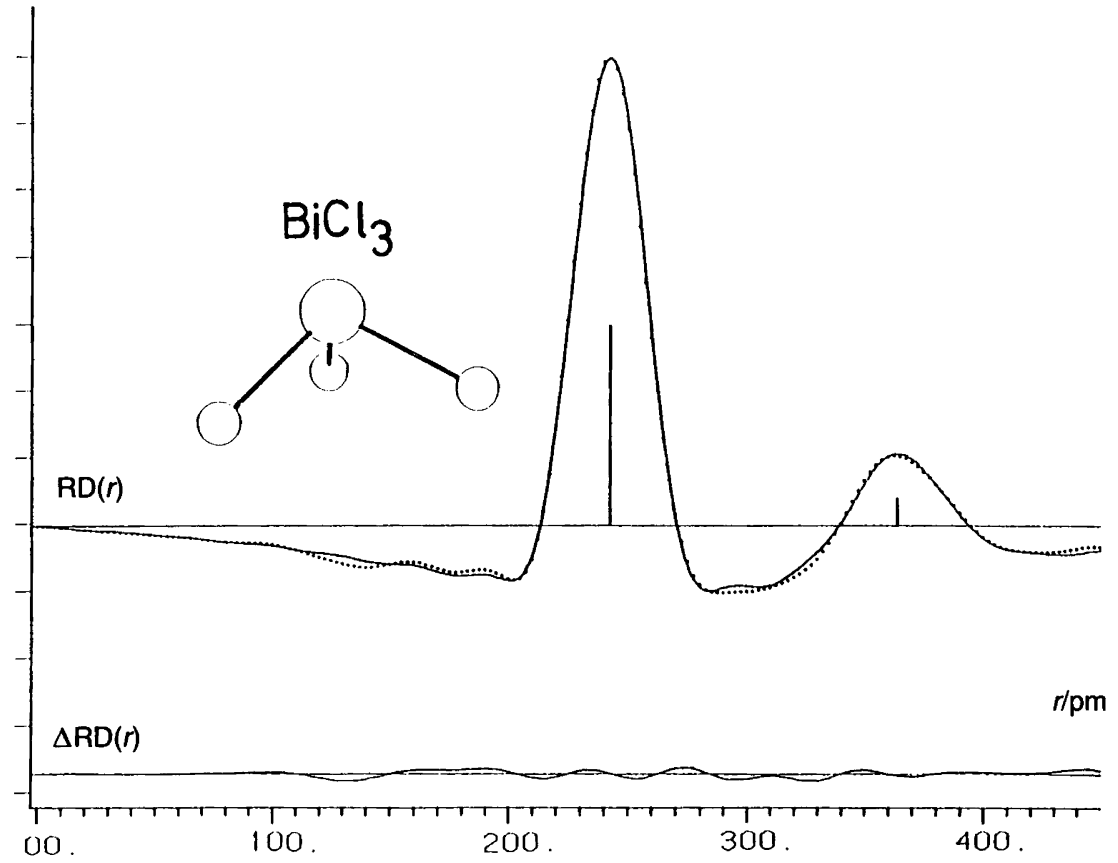

Fig. 2. Full line: calculated radial distribution (RD) curve for $\mathrm{BiCl}_{3}$. Dots: experimental RD curve. Below: Difference curve. Artificial damping constant $k=20 \mathrm{pm}^{2}$.
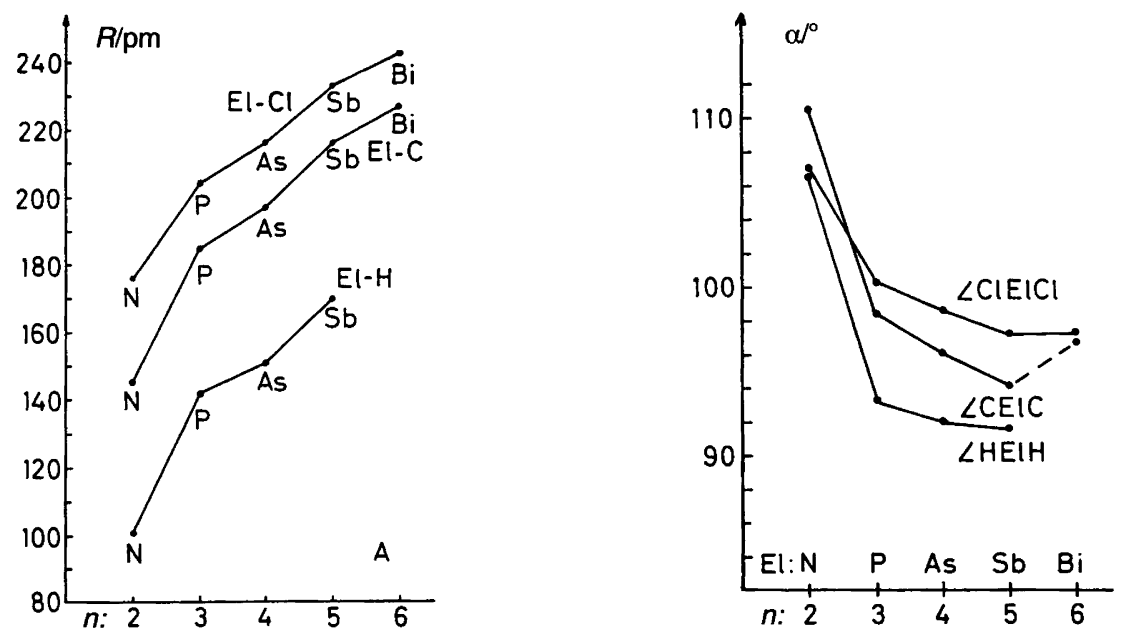

Fig. 3. Bond distances and valence angles of the gaseous compounds $\mathrm{ElH}, \mathrm{El}\left(\mathrm{CH}_{3}\right)_{3}$ and $\mathrm{ElCl}$ where $\mathrm{El}$ is a Group 15 element. The valence angle in $\mathrm{Bi}\left(\mathrm{CH}_{3}\right)_{3}$ is very uncertain: $\angle \mathrm{CBiC}=96.7(10)^{\circ}$.

teractions may presumably be described as weak electron donor/acceptor bonds, $\mathrm{Cl} \rightarrow \mathrm{Bi}$. As a result the average $\mathrm{ClBiCl}$ angle is reduced by about $6^{\circ}$ and the average $\mathrm{Bi}-\mathrm{Cl}$ bond distance increased by about $8 \mathrm{pm}$.

The bicapped trigonal prismatic coordination 


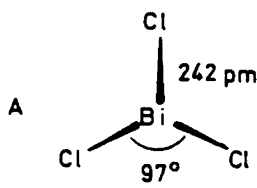

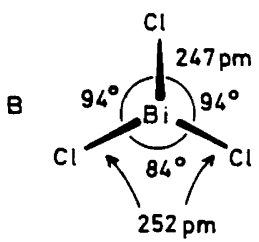

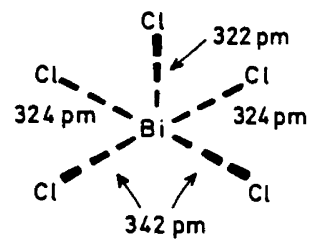

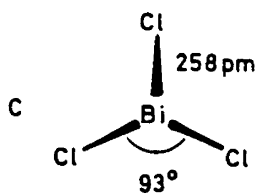

Fig. 4. (A) The structure of $\mathrm{BiCl}_{3}$ in the gas phase. (B) The coordination polyhedron of $\mathrm{Bi}$ in crystalline $\mathrm{BiCl}_{3}$. To the left the $\mathrm{Bi}$ atom and the three covalently bonded $\mathrm{Cl}$ atoms. The $\mathrm{Bi}$ is above the $\mathrm{Cl}_{3}$ plane. To the right the cap consisting of five $\mathrm{Cl}$ atoms with secondary bonds to $\mathrm{Bi}$. The coordination polyhedron may be described as a trigonal prism with two face bridging $\mathrm{Cl}$. Interatomic distances and angles have been averaged to $C_{\mathrm{s}}$ symmetry. (C) Coordination polyhedron of $\left[\mathrm{NH}_{2}\left(\mathrm{C}_{2} \mathrm{H}_{5}\right)_{2}\right]_{3}\left[\mathrm{BiCl}_{6}\right]$. The coordination is distorted octahedral with three covalently bonded $\mathrm{Cl}$ atoms below the $\mathrm{Bi}$ atom (left) and three datively bonded $\mathrm{Cl}^{-}$ions above (right).

around $\mathrm{Bi}$ is indicated in Fig. 4B. It is seen that the two bonds that are anti (or near-anti) to the strongest (shortest) secondary bonds suffer the greatest elongation and span the smallest valence angle.

The coordination around $\mathrm{Bi}$ in diethylammonium hexachlorobismuthate(III), $\left[\mathrm{NH}_{2}\left(\mathrm{C}_{2} \mathrm{H}_{5}\right)_{2}\right]_{3}$ $\left[\mathrm{BiCl}_{6}\right]$, is shown in Fig. $4 \mathrm{c}{ }^{12}$ The $\mathrm{Bi}$ atom resides on a $C_{3}$ axis, the coordination being distorted octahedral. The three secondary $\mathrm{Bi}-\mathrm{Cl}$ bond distances are $289.2(7) \mathrm{pm}$, i.e. about $30 \mathrm{pm}$ shorter than in solid $\mathrm{BiCl}_{3}$, perhaps because $\mathrm{Cl}^{-}$ions are better electron donors than (approximately) neu- tral $\mathrm{Cl}$ atoms. The covalent $\mathrm{Bi}-\mathrm{Cl}$ bond lengths have increased by about $16 \mathrm{pm}$ and the angle between them has been reduced by about $4^{\circ}$. The presence of an electron lone pair on $\mathrm{Bi}$ presumably prevents the adoption of octahedral symmetry with six equal metal- $\mathrm{Cl}$ distances as in $\left[\mathrm{SnCl}_{6}\right]^{2-}$.

Acknowledgement. We wish to dedicate this article to Professor Otto Bastiansen who has done so much to promote collaboration between the gasphase electron diffraction groups in Budapest and Oslo. We are grateful to the Norwegian Research Council for Science and the Humanities for financial support.

\section{References}

1. Bürgi, H.-B., Stedman, D. and Bartell, L. S. J. Mol. Struct. 10 (1971) 31.

2. Hedberg, K. and Iwasaki, M. J. Chem. Phys. 36 (1962) 589.

3. Konaka, S. and Kimura, M. Bull. Chem. Soc. Jpn. 43 (1970) 1693; Ugarov, V. V., Kalaichev, Yu. Sh. and Petrov, K. P. J. Struct. Chem. 26 (1985) 294; Deyanov, R. Z., Petrov, K. P., Ugarov, V. V., Shchedrin, B. M. and Rambidi, N. G. J. Struct. Chem. 26 (1985) 698; Spiridonov, V. P. and Gershikov, A. G. J. Mol. Struct. 140 (1986) 173.

4. Konaka, S. and Kimura, M. Bull. Chem. Soc. Jpn. 46 (1973) 404.

5. Hargittai, I., Tremmel, J. and Kolonits, M. Hung. Sci. Instrum. 50 (1980) 31.

6. Tremmel, J. and Hargittai, I. J. Phys. E 18 (1985) 148.

7. Hargittai, I. and Hargittai, M. J. Mol. Struct. 15 (1973) 399.

8. Schäfer, L., Yates, A. C. and Bonham, R. A. J. Chem. Phys. 55 (1971) 3055.

9. Haaland, A. J. Mol. Struct. 97 (1983) 115.

10. Bayersdorfer, L., Engelhardt, U., Fischer, J., Köhne, K. and Jander, J. Z. Anorg. Allg. Chem. $366(1969) 169$.

11. Nyburg, S. C., Ozin, G. A. and Szymanski, J. T. Acta Crystallogr., B 27 (1971) 2298.

12. Lazarini, F. Acta Crystallogr., Sect. C43 (1987) 637.

Received November 10, 1987. 